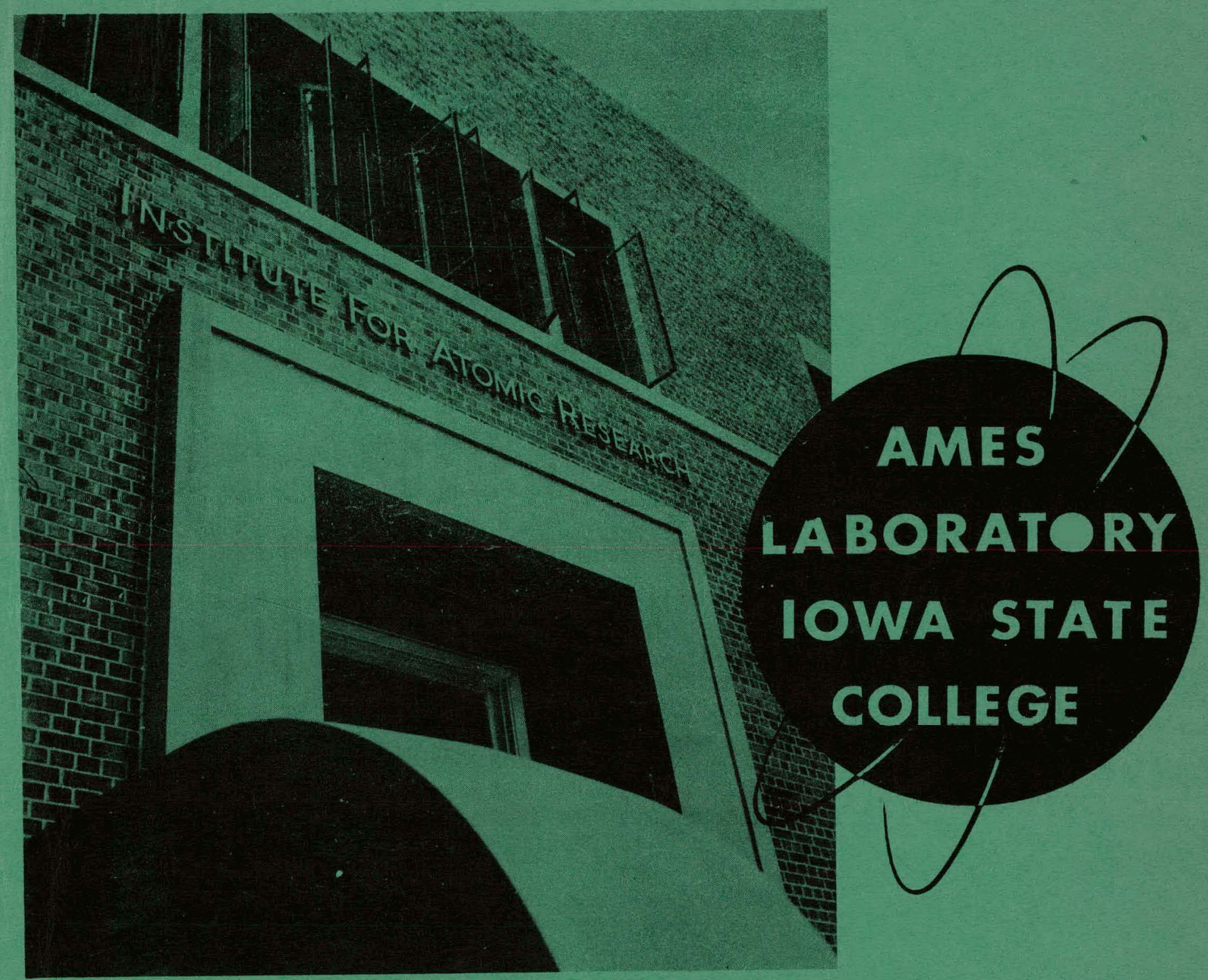

SEPARATION OF HAFNIUM FROM ZIRCONIUM USING TRIBUTYL PHOSPHATE 


\section{DISCLAIMER}

This report was prepared as an account of work sponsored by an agency of the United States Government. Neither the United States Government nor any agency Thereof, nor any of their employees, makes any warranty, express or implied, or assumes any legal liability or responsibility for the accuracy, completeness, or usefulness of any information, apparatus, product, or process disclosed, or represents that its use would not infringe privately owned rights. Reference herein to any specific commercial product, process, or service by trade name, trademark, manufacturer, or otherwise does not necessarily constitute or imply its endorsement, recommendation, or favoring by the United States Government or any agency thereof. The views and opinions of authors expressed herein do not necessarily state or reflect those of the United States Government or any agency thereof. 


\section{DISCLAIMER}

Portions of this document may be illegible in electronic image products. Images are produced from the best available original document. 
$\underline{U} \underline{N} \underline{C} \underline{L} \underline{A} \underline{S} \underline{S} \underline{I} \underline{F} \underline{I} \underline{E} \underline{D}$

\title{
ISC -682
}

$\perp$

\section{SEPARATION OF HAFNIUM FROM ZIRCONIUM \\ USING TRIBUTYL PHOSPHATE}

by

R. P. Cox and G. H, Beyer

December 23, 1955

\begin{abstract}
Ames Laboratory
at

Iowa State Callege

F. H. Spedding; Director

Contract $W-7405$ eng. 82
\end{abstract}

$\underline{U} \underline{N} \underline{\mathrm{C}} \underline{\mathrm{I}} \underline{\mathrm{A}} \underline{\mathrm{S}} \underline{\mathrm{S}} \underline{\mathrm{I}} \underline{\mathrm{F}} \underline{\mathrm{I}} \underline{\mathrm{E}} \underline{\mathrm{D}}$ 
This report is distributed according to the category Chemistry as listed in TID-4500, July. 15, 1955.

The Atomic Energy Commission makes no representation or warranty as to the accuracy or usefulness of the information or statements contained in this report, or that the use of any information, apparatus, method or process disclosed in this report may not infringe privately-owned rights. The Commission assumes no liablifty with respect to the use of, or for damages resulting from the use of, any information, apparatus, method or process disclosed in this report.

Reproduction of this information is encouraged by the United States Atomic Energy Commission. Arrangements for your republication of this document in whole or in part should be made with the author and the organization he represents.

Printed in USA. Price 15 cents. Avallable from the

Office of Technical Services U. S. Department of Commerce Washington $25, \mathrm{D}$. C. 


\section{SEPARATION OF HAFNIUM FROM ZIRCONIUM \\ USING TRIBUTYL PHOSPHATE}

bÿ

R. P. $\operatorname{Cox}^{1}$ and G. H. Beyer ${ }^{2}$

Abstract

The separation of hafnium from zirconium using tributyl phosphate offers interesting alternatives to present methods for making reactor-grade zirconium. Feed solution for the extraction step can be prepared from the reaction product of caustic and zircon sand.. The purifled zirconium can be converted into a variety of compounds, depending on the process chosen for reduction to the metal. It may be that future developments w11l show tributyl phosphate extraction to have advantages in new plants for the production of low-hafnium zirconium metal.

Zirconium has become an important construction material for nuclear reactors because of 1 ts corrosion resistance, structural strength, and low neutron absorption. Approximately 2.5 per cent of hafnium is assoclated with zirconium in naturally-occurring zirconlum ores. Since hafnium has an abnormally high neutron absorption cross-section, it must be removed from zirconium used in nuclear reactors. The close chemical similarity of hafnium and zirconium makes separation by ordinary chemical techniques difficult. This has led to the development of a number of physical separation methods, notably solvent extraction.

As early as 1947, Fisher and Chalybaeus (4) reported the separation of hafnium from zirconium by distribution between two solvents. By 1953 Miller (6) was able to state that "separated, hafnlum-free zirconlum oxide can be produced for well under $\$ 5$ per pound to which should be added the cost of converting to zirconium metal." Although the details of the hafnium removal process are classifled, it is stated that zirconium tetrachloride is used as feed and zirconium dioxide is obtained as product. After chlorination this product is reduced with magnesium by the Kroll process (5).

1M. W. Kellogg Company, New York

2 Department of Chemical Engineering, Iowa State College, Ames, Iowa 
SEPARATION OF HAFNIUM FROMSIZIRGONIUM USING TRIBUTYL PHOSPHATE

This paper reports experimental work on the use of tributyl phosphate as a solvent for the separation of hafnium from zirconium. With the development of a method for opening up zircon sand with caustic ( 1 , and a method for the reduction of zirconium tetrafluoride with calcium (2), there now exists an alternate for each step of the currently-used process for manufacturing hafnium-free zirconium. It may be that future developments will show some of these alternate processes worthy of incorporation in new industrial plants.

The schematic flow diagram of a possible zirconium process is presented in. Higure i. Zircon sand, treated with caustic, was converted into aqueous zirconium nitrate solution and extracted with tributyl phosphate. The solvent preferentially dissolved the zirconium, leaving hafnium in the aqueous phase. The purified zirconium was stripped from the solvent with sulfuric acid solution, and the solvent reused. Nitric acid was recovered from both the extractor raffinate and the stripped product by evaporation to dryness. Zirconium sulfate was then converted to either the oxide or the fluoride, as a preliminary step in metal preparation.

For simplicity, the zirconium-hafnium solution before extraction will be referred to as zirconium. There was no change in the relative quantities of hafnium and zirconium in any processing step except extraction. Since the exact chemical natures of the zirconium compounds present in the process are complex and unknown, the simplest expression will be used, e.g. zirconium nitrate.

Zircon sand, $\mathrm{ZrSiO}$, was reacted with molten caustic soda by heating the two materials in a furnace and the reaction mass then cooled. The product was a light, granular material soluble in mineral acids. Although the chemistry of the reaction is not well understood, the major constituents of the reaction product were probably sodium zirconate and sodium silicate. Other insoluble silicates, excess caustic, and unreacted zircon sand were also present. Washing with $2-4$ gallons of cold water per pound of reaction product followed by centrifugal setting removed the soluble silicates and excess caustic. At the same time the sodium-zirconate was largely coverted to an hydrated zirconium oxide. Feed for the extraction step was made from this washed reaction product which could be dissolved in nitric, hydrochloric, or sulfuric acids.

Dissolution of the washed reaction product directly in nitric acid was not always successful. With the addition of nitric acid large quantities of hydrated silica appeared, causing the entire mass to become extremely gelatinous. Often the mass 


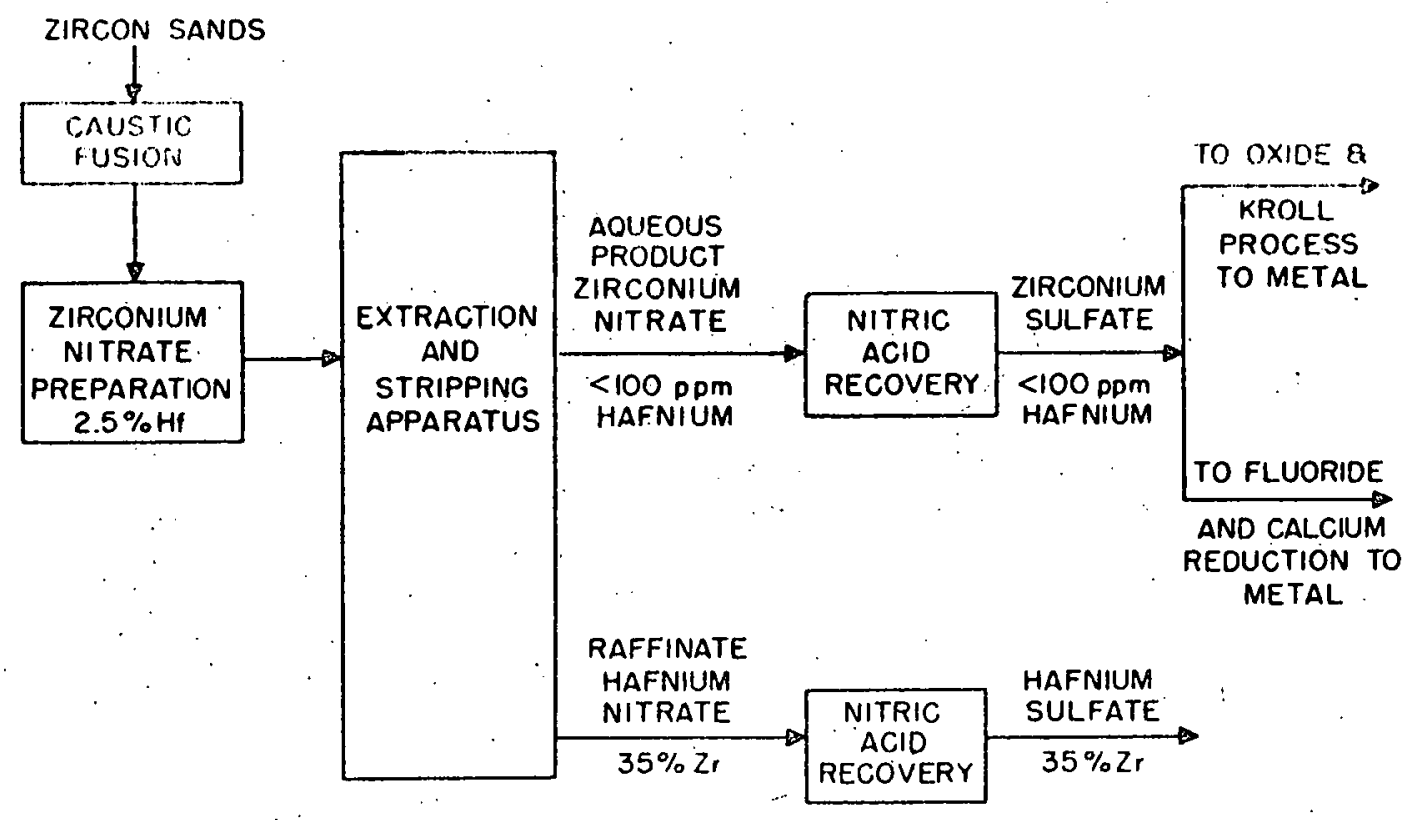

FIG.I-SCHEMATIC FLOW DIAGRAM OF ZIRCONIUM PROCESS 
became so thick that it appeared to be a solid rather than a 1iquid. It was possible to eliminate this gelatinous silica by evaporation of the solution to dryness and redissolving in nitric acid. The gel was apparently dehydrated to insoluble silicates that were filtered from the nitric acid solution. However, difficulties were again encountered. When extraction was attempted. Even though no gel appeared in the aqueous solution, a heavy gelatinous mass formed in several stages of the extraction apparatus. The use of nitric acid dissolution gave feed solutions that were erratic in extraction behavior, and no consistently suitable feed was obtained by this method.

Dissolution of the washed reaction product in either hydrochloric acid or sulfuric acid gave zirconium nitrate solution suitable for extraction. Solution in hydrochloric acid gave a product that could be easily purified of the silicates and many other impurities, as the silicates did not immediately form a gelatinous mass. The solution was first filtered to remove unreacted zircon sand and granular silicates. The zirconium could be markedly purified by crystallization of zirconyl chloride. The acid solution was concentrated by evaporation to $6 \mathrm{M}$. free hydrochloric acid and allowed to cool: The solubility of zirconyl chloride in $6 \mathrm{~N}$ hydrochloric acid is 100 times greater at the bolling point than at room temperature. Upon cooling, large white crystals of zirconyl chloride hexahydrate formed which could be easily separated by filtration. The zirconyl chloride could be dissolved in water, zirconium precipitated as the hydroxide, filtered. and dissolved in nitric acid. Although this procedure produced satisfactory extraction feed, it did not prove to be as economical as sulfuric acid dissolution.

Dissolution of the reaction product in sulfuric acid, as shown in Figure 2, proved to be the most economical method tested. Concentrated acid was added to the washed reaction product in an agitated vessel and stirred for 20 minutes. The reaction was highly exothermic. Violent bolling occurred, but soon subsided, giving a paste of zirconium sulfate. The high temperatures reached, combined with the dehydrating action of sulfuric acid, expedited silica removal. The paste was dissolved in water and filtered to remove silica and unreacted zircou sand. Approximately two pounds of sulfuric acid were used per pound of reaction product to give 0.5 pound of zirconium as the sulfate., Less sulfuric acld would be required for normal zirconium sulfate production, but this quantity was necessary for dehydrating silica to prevent emulsion formation during extraction. Aqueous ammonium hydroxide was added directly to the zirconium sulfate solution, quantitatively precipitating the zirconium as the hydroxide. 


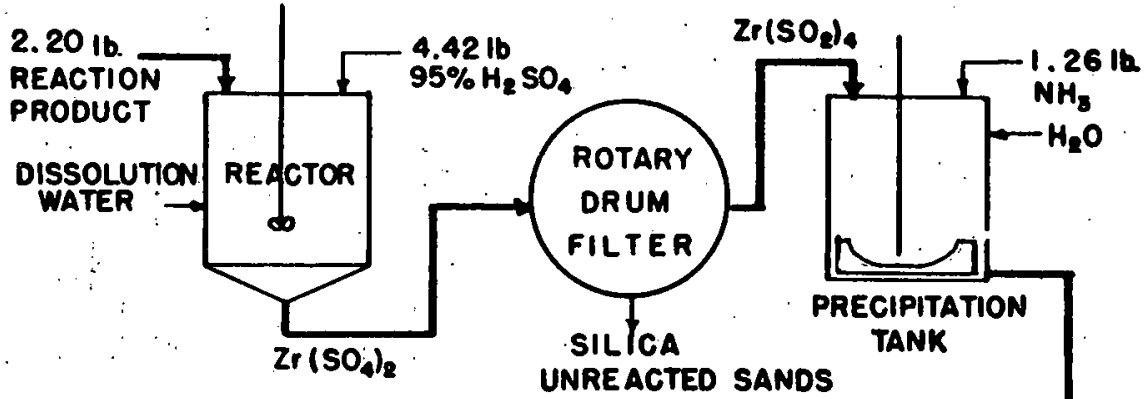

UNREACTED SANDS

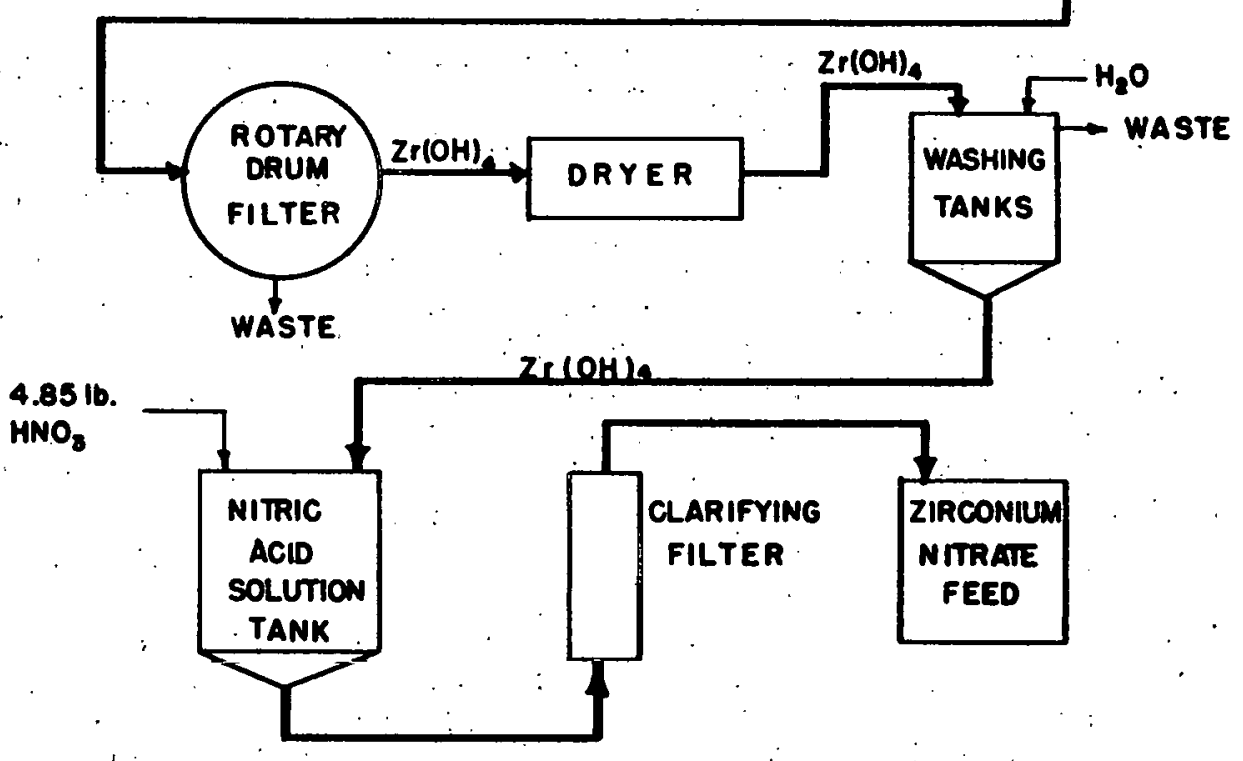

BASIS: $1.0 \mathrm{lb} . \mathrm{Zr}$ AS NITRATE

FIG. 2 FLOW SHEET FOR PREPARATION OF ZIRCONIUM NITRATE FEEO SOLUTION 
The presence of large quantities of sulfate in the extractor feed markediy lowered the separation factor. It was difficult to effectively wash sulfate Ion from the gelatinous hydroxide cake by elther decantation or repulping. Fortunately a partial drying of the hydroxide cake gave a materlal that shattered upon water addition into a sand-like form. It should be noted, however, that hydroxide precipitated from zirconium sulfate solutions containing more than 10 grams of zirconium per liter did not yleld the desired form upon drying. At higher concentrations 1t was postulated that a basic zirconium sulfate was precipitated. Washing of the dried hydroxide cake proved to be a simple operation, as the material acted much as ordinary sand. It was found that the $304 / \mathrm{Zr}$ ratio could be quickly reduced to 0.17 using little more water than theoretical decantation calculations would predict. Subsequent washing did not reduce the sulfate content. However, testing of this feed solution showed this small amount of sulfate had no effect upon separation factor.

The washed granular hydrated oxide was dissolved in nitric acid to give the desired extraction feed solution composition. The solution was passed through a clarification filter to remove the small amount of solids that did not dissolve in nitric acid.

The extraction separation of zirconium and hafnium nitrates was accomplished using tributyl phosphate solvent diluted with 40 per cent $n$-heptane to shorten the time required for separation of phases. The feed solution contained about 2.5 per cent hafnium plus small quantities of other impurities such as iron. It was necessary to reduce the hafnium content to less than 100 parts per mililon, with removal of substantial quantities of the other impurities. Figure 3 summarizes the method employed.

The aqueous feed was introduced at an intermediate point in the extractor where it combined with aqueous serub solution flowing countercurrentiy to the tributyl phosphate olvent. In the extraction section the tributyl phosphate, referred to as TBP, selectively picked up zirconlum from the combined feed and scrub streams, leaving a high-hafnium concentrate in the raffinate. In the scrub section the aqueous scrub solution removed essentially all the hafnlum from the solvent, carrying it back toward the feed point, together with a portion of the zirconium. Singlestage separation factors gave a value of approximately 15 for the expression (HF/Zr) aqueous/(HF/Zr) TBP.

ar

The separation was markediy affected by the nitric acid concentration. The concentrations of acid were so chosen that good selectivity was obtained with minimal solvent degradation. 


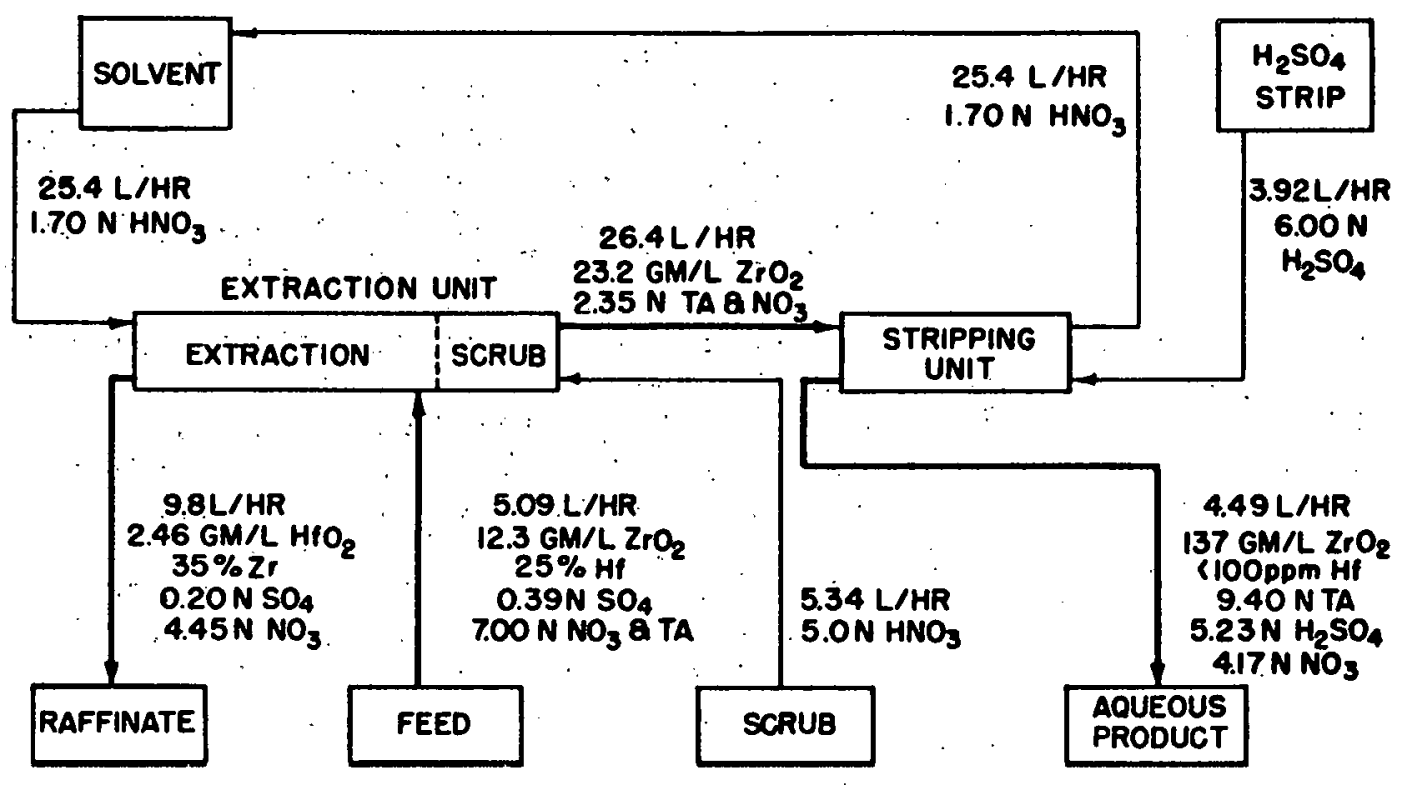

BASIS - I LB OR 454 GM Zr /HR

$T A=$ TOTAL ACIDITY

FIG.3 - FLOW DIAGRAM FOR EXTRACTION OF HAFNIUM FROM ZIRCONIUM. 
Zirconium concentration in the feed of $1.0 \mathrm{M}$ or 123 grams of equivalent oxide per liter was the maximum conveniently obtained. All concentrations of hafnium and zirconium were expressed as oxide because of uncertainty as to exactly what compounds were present in solution.

A raffinate containing 65 per cent hafnium was produced, corresponding to a zlrchnium recovery of 98.7 per cent. It would be possible to produce $99+$ per cent hafnium by the addition of more stages to the extraction section. Purification of the zirconium from other impurities such as iron, copper; and titanium also occurred since these materials remained in the aqueous phase.

I'he 'IBP solvent containing purified zirconium was stripped in a second extractor with a $3 \mathrm{M}$ solution of sulfuric acid. Acid was used in preference to water since depletion of the nitric acid In the solvent was minimized. Sulfuric acid was also more selective for zirconium than water, reducing the quantity of strip solution. The stripped solvent was returned to the extraction unit for reuse.

Analytical treatment of the extraction and stripping operation was difficult because of the complex systems involved. Since the distipibutions of hafnium and zirconium are affected by composition as well as concentration, the method used to determine equilibrium data was to operate a mixer-settler system near the desired operating conditions and to sample from settlers at equilibrium. The composite equilibrium line thus obtained was used to calculate the flow ratios for a small change in separation. It was found that 12 theoretical stages, with feed to the tifth stage from the scrub end of the extractor, gave the separation and flows indicated.

An example of a stagewise analysis is shown in Table 1. It will be noted that if the solvent enters at less than its equilibrium nitric acid concentration some loss in zirconium selectivity occurs at the raffinate end of the extractor. It is therefore desirable to maintain the equilibrium acid concentration in the entering solvent, or additional stages will be required for the same zirconium recovery.

Mixer-settler extractors were used for both extraction and stripping. Early studies were conducted in an apparatus constructed of mixers and settlers fabricated from 2-Inch diameter test tubes connected with flexible tubing. Interface helght was controlled by the speed of the agitator. Equilibrium studies were performed in these extractors since the flexible tubes could be closed. of to allow settlers to reach equilibrium. Later extraction work was done in a commercial type mixer-settler, 


\section{Table 1}

Stagewise Analyses of Run A

\section{Stage Organic}

gm. oxide/l. $\mathrm{N} \mathrm{HNO}_{3} \frac{\mathrm{Hf}}{\mathrm{Zr}} \times 100$

\section{Aqueous}

gm. oxide/1. $\mathrm{N} \mathrm{HNO}_{3} \frac{\mathrm{Hf}}{\mathrm{Zr}} \times 100$

\begin{tabular}{rrrrrrrr}
\hline 1 & 22.2 & 1.95 & $<0.010$ & 17.5 & 5.21 & $<0.010$ \\
2 & 29.3 & 2.02 & $<0.010$ & 27.5 & 5.30 & $<0.010$ \\
3 & 31.4 & 2.03 & $<0.010$ & 33.5 & 5.46 & $<0.010$ \\
4 & 31.8 & 2.03 & 0.043 & 34.9 & 5.46 & 0.24 \\
5 & 32.2 & 2.03 & 0.11 & 52.8 & 5.15 & 3.6 \\
6 & 21.1 & 1.99 & 0.60 & 30.8 & 5.15 & 6.8 \\
7 & 13.7 & 1.93 & 0.27 & 19.9 & 5.05 & 9.8 \\
8 & 7.66 & 1.89 & 1.9 & 11.6 & 4.97 & 20. \\
9 & 4.14 & 1.86 & 4.8 & 8.06 & 4.97 & 36. \\
10 & 1.98 & 1.83 & 10. & 3.32 & 4.75 & 67. \\
11 & 1.03 & 1.77 & 23. & 3.71 & 4.52 & 110. \\
12 & 0.66 & 1.68 & 32. & 3.14 & 4.12 & 140. \\
13 & 0.46 & 1.50 & 42. & 2.99 & 3.49 & 130. \\
14 & 0.29 & 1.18 & 28. & 3.54 & 2.56 & 72. \\
\hline
\end{tabular}


such as developed at Knolls Atomic Power Laboratory, where Interfaces.were automatically controlled. Fourteen actual stages were found to be equivalent to approximately 12 theoretieal stages.

W1th extended use, the tributyl phosphate solvent degraded somewhat às evidenced by an increase in phase separation time. It was 180 noted that small amounts of zirconium were slowly complexed by the solvent so that stripping was ineffective in removing these last traces. Approximately 30 complete solvent cycles were completed before this degradation became ident, although the effect was probably one of $t$ ime rather than number of cycles. The solvent could be regenerated by a simple procedure. The solvent was first stripped of the nitric ac1d by a countercurrent wash with water. The washed solvent was then contacted twice with one-fifth 1 ts volume of $0.2 \mathrm{M}$ sodium hydroxide solution. Following the caustic washes, two water washes were employed to remove traces of caust1c. The regenerated solvent was acidified with nitric acid and reused. No permanent degradation was detected. Solvent losses were quite low, amounting to roughly that lost by solubility in the aqueous phase.

Both the raffinate and stripper product streams contain large quantities of nitric acid which must be recovered. In each case the streams were vaporated to dryness. Sufficient sulfate was present in the feed to form soluble sulfates of. the hafnium-zirconium plus other impurities in the raffinate. The stripper product was similarly evaporated, the more volatile nitric acid leaving overhead and the sulfate forming solld zirconium sulfate. The over-all recovery of nitric acid from the tno streams was about 95 per cent.

The zirconium sulfate formed from evaporation of the stripper product was a white crystalilne solid of high purity. Thls material could be converted to a number of other compounds. If zirconium metal was to be produced, e1ther the oxide or the fluoride could be prepared. Zirconium tetrafiuoride was made by addition of 70 per cent aqueous hydrofluoric acid. The reaction was allowed to proceed for 10 minutes and then the crystaline zirconium tetrafluorlde filtered to remove sulfuric acid. The filter cake was washed with ethanol or acetone to remove 11quid adhering to the crystals. Washing with water was avolded because of the solubility of the fluoride in dilute sulfuric acid or water. 
The zinc tetrafluoride was dried in the presence of anhydrous hydrogen fluoride to remove the water of hydration and then bomb-reduced to the metal. Four samples of metal gave A-Rockwell hardness values of $45,45.5,50$ and 52 (compared to the usual specification of 50 ).

Zirconium oxide for Kroll reduction was also prepared from the sulfate. The zirconium sulfate was dissolved in water, and zirconium hydroxide was precipitated by: ammonia. The hydroxide was filtered, washed, dried, and calcined to the oxide. The Kroll process would then chlorinate the oxide to zirconium tetrachloride and reduce the product to a metal sponge with magnesium. 


\section{LITERATURE C.ITED}

1. Beyer, G. H., Splnk, D. R., West, I. B. and W1lhelm, H..A. Caustic treatment of zircon sand. Chemical Engineering Progress Symposium Series, No. 12, Vol. 50, 67-71 (1954).

2. Carlson, O. N., Schmidt, F. A. and Wilhelm, H. A. Preparation of zirconium and hafnium metals by bomb reduction of their fluorides. (In preparation)

3. Cux, R. P. Pliot plant extraction of hafrilum from zirconlum: Unpublished $\mathrm{Ph} . \mathrm{D}$. Thesis, Ames, Iowa, Iowa State College L1brary. 1954.

4. Fisher, $W$, and Chalybaeus, $W$. The separation of Inorganic mixtures by distribution between two solvents. III. The separation of hafnium from zirconium by distribution. Z. anorg. Chem. 255, 79-100 (1947).

5. Kroll, W. J., Stephens, W. W. and Holmes, H. P. Production of malleable zirconium on a pilot plant scale, Journal of Metals, Vol. 188, 1455 (1950).

6. Milier, E. C. Zirconium and nuclear reactors. Zirconium and Zirconium Alloys, American Soclety of Metals; 327-340, Cleveland, Ohio, 1953.

7. Peterson, H. C. Separation of hafnium and zirconium by liquidliquid extraction. Unpublished Ph.D. Thesis. Ames; Iowa, Iowa State College Library. 1953. 


$$
1-14
$$

\section{THIS PAGE}

\section{WAS INTENTIONALLY LEFT BLANK}

